\title{
Publisher Correction: Exercise-induced myokines and their effect on prostate cancer
}

Jin-Soo Kim, Daniel A. Galvão, Robert U. Newton (1), Elin Gray (1) and Dennis R. Taaffe

Correction to: Nature Reviews Urology https://doi.org/10.1038/s41585-021-00476-y, published online 22 June 2021.

In the original version of the article, the name of author Elin Gray was misspelled as Elin Grey. The author's name has now been updated to the correct spelling in the HTML and PDF versions of the article.

https://doi.org/10.1038/s41585-021-00501-0 I Published online 6 July 2021

(c) Springer Nature Limited 2021 